(2) Open Access Full Text Article

\title{
Improving Patient Health Literacy in Hospitals - A Challenge for Hospital Health Education Programs
}

\author{
Ming-Jye Wang (iD) ${ }^{1,2}$ \\ Yi-Ting Lo ${ }^{3}$ \\ 'Department of Secretariat, National \\ Taiwan University Hospital Hsin-Chu \\ Branch, Hsinchu, Taiwan; '2Department of \\ Healthcare Management, Yuanpei \\ University of Medical Technology, \\ Hsinchu, Taiwan; ${ }^{3}$ Department of \\ Development and Planning, National \\ Taiwan University Hospital Hsin-Chu \\ Branch, Hsinchu, Taiwan
}

\begin{abstract}
Background: The health literacy of hospital patients has become a very important issue, especially in the face of emerging infectious diseases. The design of and measures used by hospitals, however, have not yet taken into account whether patients can develop their health literacy through the process of medical treatment. Hospitals should take on this role as part of health education programs.

Methods: A cross-sectional survey was conducted at pre-admission testing center patients waiting to be hospitalized in a regional teaching hospital. A purposive sampling method was used to recruit 406 patients via self-administered questionnaires.

Results: Among the 406 participants, 36.1\% had adequate health literacy. There were significant differences in age, education attainment, and history of chronic diseases for health literacy. The ability to find and judge information on health was lower. Watching healthrelated TV programs was positively correlated with health literacy. Health literacy, health promotion literacy, and understanding information on health were positively correlated to self-care and management. $65.8 \%$ of patients did not understand the treatment for which they were being admitted. Health literacy, healthcare health literacy, the ability to judge health information were positively related to understanding the treatment.

Conclusion: Health literacy is a critical facilitating factor in improving self-care and management and understanding treatment on admission. Health education programs cannot, however, be one-size-fits-all. To help patients change their behavior, the change must be made easy. To this end, health information in the form of entertainment programs and simplified materials may be useful and even necessary.
\end{abstract}

Keywords: health literacy, health information, health promotion, infectious diseases, medical treatment, hospitals

\section{Introduction}

While hospitals provide medical treatment, they also have a role in helping patients understand their conditions and treatment. The importance of health literacy (HL) has become a more important issue in modern hospitals in the face of emerging infectious diseases. Hospitals are no longer just places to care for patients, but can be seen as independent health centers for the community. If the health center promote, organize, implement and evaluate health education activities, ${ }^{1}$ this could have a long-term influence on the behavior of patients and their relatives in improving their health. Hospitals, therefore, have a potential role in promoting people's health, and in promoting health education programs, including preventive strategies. ${ }^{2}$ This may be the time for health providers to empower patients to increase their HL. ${ }^{3}$
Correspondence: Ming-Jye Wang Department of Secretariat, National Taiwan University Hospital Hsin-Chu

Branch, No. 25, Lane 442, Sec. I, Jingguo

Road, Hsinchu, 300, Taiwan

Tel +886 3532615 I Ext. 8897

Fax +88635329157

Email jye9129@gmail.com 
Health education and HL have a close relationship. The intervention of health education to improve HL and increase health-related knowledge and self-care is very important. In fact, improving HL becomes one of the main performance indicators when evaluating health education policies, activities and interventions. ${ }^{4}$ A complete healthcare service includes the fields of disease prevention, screening, treatment, and prognosis. Many of the professional terms and concepts involved are not easily understood by non-medical professionals. How patients communicate with professional health providers has been shown to influence a wide array of outcomes-both emotional and physiological - and may have a bearing on whether a patient receives appropriate healthcare. ${ }^{5} \mathrm{HL}$ is, therefore, an important factor in effective communication between physician and patient. ${ }^{6}$

$\mathrm{HL}$ is a basic requirement if people are to effectively use health-care resources. According to a survey conducted by the Ministry of Health and Welfare in Taiwan, $51.6 \%$ of adults had insufficient and limited $\mathrm{HL}^{7}$ Inadequate HL results in many adverse health outcomes. Studies have shown that patients with inadequate HL have a higher prevalence of chronic diseases, a higher rate of hospitalization and emergency medical treatment, are more likely to make errors with medication, are less likely to use preventive health services, have insufficient awareness of their illness, and have poor self-management skills. ${ }^{89}$ These factors increased medical expenditure by $3-5 \%{ }^{10}$ Conversely, patients with a basic level of HL are more confident in asking questions of medical staff and seek effective and rapid problem-solving methods. ${ }^{11}$

When patients have the ability to participate and communicate, this can significantly shape health outcomes. Patient engagement has been widely used as a term to describe the design of interventions to improve patient activities, encourage healthy behaviors (such as seeking health information or preventive services), and to increase patients' knowledge, skills and confidence in managing their health. ${ }^{12}$ The Health confidence (HC) scale is a simple measure of patient engagement and better health outcomes. ${ }^{13}$ It is also one of the few measures that sets out to directly measure self-care confidence. ${ }^{14} \mathrm{HC}$ is positively associated with patients' HL and their ability to access the care they need. ${ }^{15,16}$ Patients who are more confident in taking care of their health tend to cost less than those who are not confident, and they have better health outcomes and ability to achieve their health goals. ${ }^{14}$
Average life expectancy is gradually increasing, but the body's natural aging process still affects health. For patients whose condition cannot be cured, health education - for patients and their relatives - can prepare them for discharge, improve their self-care, and improve quality of life. From the perspective of the medical care system, a large number of hospital readmissions or complications can be avoided. ${ }^{2}$ Self-management, therefore, may be one means of bridging the gap between patients' needs and the capacity of health-care services to meet those needs. ${ }^{17}$

The diversity of HL may become a challenge for hospital health education. ${ }^{18}$ Studies have shown that there is often a considerable gap between the information provided by health providers and what patients need or can understand. ${ }^{19}$ All designs and measures used by hospitals, however, have not yet taken into account whether patients can develop their HL through the process of medical treatment. In this way, hospitals would provide medical treatment and improve patient's HL in parallel. ${ }^{20}$ To achieve this, a meaningful relationship between patients and caregivers is hugely important. Hospitals need to evaluate and understand patients' $\mathrm{HL}, \mathrm{HC}$, general selfefficacy (GSE), patient-physician interaction (PPI), and self-care and management (SCM). When hospitals deliver health education or instruction, these will help make resources and intervention measures more appropriate and effective.

The aims of this study were to: 1) investigate the relationship between the HL of in-patients and their characteristics; 2) analyze the relationship between HL, GSE, PPI, HC and SCM of in-patients; 3) examine the relationship between HL, GSE, PPI, HC and the degree of understanding treatment on admission (UTA). As patients' needs have grown more complex, these findings may provide insights for hospitals to improve patient health education programs, intervention measures, and quality of patient care resulting in truly patient-centered holistic healthcare.

\section{Methods}

\section{Study Participants}

The participants in this study were waiting to be hospitalized at pre-admission testing center (PAT) in a regional teaching hospital in Hsinchu City, Taiwan. The HL scale, GSE scale, PPI scale, HC scale and SCM scale were used. A purposive sampling method was used to recruit patients with consent from 23 July to 20 August 2019. Researchers 
explained the purpose of this study briefly prior to distribution of the questionnaires; a total of 408 questionnaires were actually distributed, and 406 completed selfadministered questionnaires were collected.

\section{Research Scale Design}

Health literacy (HL) scale: The HL-SF12 used in this study was developed from HLS-EU-Q47 $7^{21,22}$ using nationwide data on general public and patients in general hospitals in Taiwan. This comprehensive HL-SF12 was a valid and easy-to-use tool for assessing patients' $\mathrm{HL}$ in the hospitals. ${ }^{23}$ The HL-SF12 contained 12 items, each scored on a 5 -point scale (from $1=$ very difficult to $5=$ very easy), using Cronbach's $\alpha$ value $=0.95$ for the reliability analysis.

The development of the HLS-EU-Q followed a concept validation approach proposed for an integrated model of HL by Sorensen et al. ${ }^{24}$ The model starts from a definition of HL that integrates the different aspects of HL as identified in the literature, stating that:

Health literacy is linked to literacy and entails people's knowledge, motivation and competencies to access, understand, appraise, and apply health information in order to make judgments and take decisions in everyday life concerning healthcare, disease prevention and health promotion to maintain or improve quality of life during the life course. ${ }^{24}$

The four types of competencies are Access to health information, Understanding that information, Appraising the information in the context of one's own health problems, and Applying the information to oneself. ${ }^{24}$

The three domains of health continuum are to process, understand, appraise, and apply the medical information as a patient in the healthcare (HC-HL) setting; to assess, understand, appraise, and apply information on risk factors for health as a person at risk of disease in the disease prevention (DP-HL) system; and to update, understand, appraise, and apply oneself on determinants of health in the social and physical environment as a citizen of health promotion (HP-HL) in social and physical environment. ${ }^{24}$ The HL-SF 12 covered the 12 sub-scales of the HLS-EU matrix $3 \times 4$ cell with three to five items in each scale. A reliability analysis test was used to examine each scale, using Cronbach's $\alpha$ value $=0.76-0.88$.

General self-efficacy (GSE) scale: Self-efficacy makes a difference in how people feel, think, and act, ${ }^{25}$ and is commonly understood as being task-specific, or domainspecific. $^{26}$ But GSE refers to global confidence in one's coping skill ability across a wide range of demanding or novel situations, which aims at a broad and stable sense of personal competence to deal effectively with all kinds of stressful situations. It may explain a broader range of human behaviors and coping outcomes when the situations are less specific. ${ }^{26}$ It might reflect a generalization across various domains of functioning in which people judge how efficacious they are, thus the higher the score on this scale, the greater is the individual's GSE.

The GSE scale used in this study was developed with reference to Schwarzer and Jerusalem ${ }^{27}$ and has been proved to have good reliability and validity. To implement health education programs effectively, adopting a broader definition of GSE is necessary. The scale has ten items rated on 5-point Likert scales (from 1 = strongly disagree to $5=$ strongly agree). The reliability of the scale is Cronbach's $\alpha$ value $=0.94$.

Patient-physician interactions (PPI) scale: The PPI is central to the process of healthcare. Good patientphysician communication has been shown to be associated with a broad range of improved outcomes of care to achieve mutual health goals. ${ }^{28}$ Effective PPI is also likely to be dependent on the assertiveness of patients themselves - that is, their confidence in their ability to interact with physicians. ${ }^{29}$

The PPI scale used in this study is based on the fiveitem Perceived Efficacy in Patient-Physician Interactions (PEPPI-5) scale. ${ }^{29}$ PEPPI is a valid and reliable measure of older patients' perceived self-efficacy in interacting with physicians. This instrument may be useful in measuring the impact of empowerment interventions to increase older patients' personal sense of effectiveness in obtaining needed healthcare. ${ }^{28}$

The PEPPI-5 consists of five items, and participants rated each item on a 5-point scale, with $1=$ not at all confident and $5=$ very confident. Total scores of the PEPPI-5 were summed to range from 5 to 25 , with higher scores representing higher perceived self-efficacy in PPI. The reliability of the scale is Cronbach's $\alpha$ value $=0.94$.

Health confidence (HC) scale: The HC scale monitors people's confidence in their ability to manage their own health and engage with health-care providers, which can also be used either clinically or for evaluation. Clinically it can help tailor interventions to individual patients' needs. For evaluation, it is used to track how much a program helps people have more control over their own health. ${ }^{30}$

The HC scale used in this study was developed with reference to Benson et al. ${ }^{31}$ The scale has four items 
rated on a 5 -point Likert scale $(1=$ strongly disagree and 5 = strongly agree). The reliability of the scale is Cronbach's $\alpha$ value $=0.88$.

Self-care and management (SCM) scale: Longer life expectancy and increasing numbers of people living with chronic conditions have shifted the daily active responsibility for disease management from health-care professionals to the individual. Indeed, patients are experts in accessing information related to their health-care needs and performing the selfmanagement tasks needed to control or reduce the impact of their health condition. ${ }^{17}$ Therefore, understanding and increasing patient SCM is a key policy focus.

The SCM scale used in this study was adapted from Manage Disease in General Scale. ${ }^{32}$ The scale has five items rated on a 5 -point scale $(1=$ not at all confident and $5=$ very confident). The reliability of the scale is Cronbach's $\alpha$ value $=0.93$.

\section{Patient Characteristics}

Patient characteristics included age, gender, educational attainment, department of admission, history of chronic disease, perceived health status (from $1=$ very bad to $5=$ very good), watching health-related TV (from $1=$ never to $5=$ often), understanding treatment on admission (UTA) (from $1=$ do not understand to $5=$ understand very well).

\section{Data Analysis}

Descriptive statistics, including mean, standard deviation and frequency, were used to explore the distribution of patient characteristics. $t$-test and one-way analysis of variance (ANOVA) were used to test the correlation between $\mathrm{HL}$ and patient demographics. Multiple regression analysis was used to analyze the independent effects of patient characteristics on the HL and to analyze the independent effects of PPI, HC, HL, and GSE on SCM/UTA. Path analysis was used to analyze the relationships among HL, GSE, PPI, and HC on SCM. Reliability analysis was used to examine the reliability of the questionnaire. All statistics were analyzed using SPSS version 22.0.

\section{Results}

\section{Study Participant Characteristics and Mean Value of Each Scale}

Of the 406 valid self-administered questionnaires, $46.6 \%$ respondents were male and $53.4 \%$ were female. $45 \%$ were 45-64 years old; $39.3 \%$ had a high school education and $33.5 \%$ had a college degree or above. Patients with a history of chronic diseases accounted for 52.8\%. 83.4\% were being treated in the Department of Surgery (Table 1).

Patients reported an average HL score of 3.66 (range 1-5) with item-specific means of $3.08-3.85 ; 36.1 \%$ of respondents

Table I Patient Characteristics and Mean Value of Each Scale

\begin{tabular}{|c|c|c|c|c|c|}
\hline Variables & $\mathbf{N}$ & $\%$ & Variables & Mean (SD) & Positive $\%^{\mathrm{a}}$ \\
\hline \multicolumn{3}{|l|}{ Sex } & Health literacy & $3.66(0.61)$ & 36.1 \\
\hline Male & 189 & 46.6 & Healthcare & $3.63(0.64)$ & 38.9 \\
\hline Female & 217 & 53.4 & Disease prevention & $3.68(0.65)$ & 47.5 \\
\hline \multicolumn{3}{|c|}{ Age (year) Mean (SD) 54.7I (I7.35) } & Health promotion & $3.69(0.67)$ & 49.5 \\
\hline$\leqq 44$ & 107 & 26.8 & Find information on health & $3.61(0.68)$ & 43.3 \\
\hline $45-64$ & 180 & 45.0 & Understand information on health & $3.73(0.65)$ & 50.5 \\
\hline $65^{+}$ & 113 & 28.2 & Judge information on health & $3.60(0.65)$ & 41.1 \\
\hline \multicolumn{3}{|c|}{ Education attainment } & Apply information on health & $3.71(0.64)$ & 50.5 \\
\hline$\leqq$ Middle school & 108 & 27.2 & General self-efficacy & $3.85(0.57)$ & 52.0 \\
\hline High school & 156 & 39.3 & Patient-physician interaction & $3.80(0.65)$ & 56.3 \\
\hline$\geqq$ College & 133 & 33.5 & Health confidence & $3.85(0.59)$ & 63.7 \\
\hline \multicolumn{3}{|c|}{ History of chronic disease } & Self-care and management & $3.76(0.66)$ & 55.4 \\
\hline Yes & 205 & 52.8 & Understanding treatment on admission & $3.08(1.00)$ & 34.2 \\
\hline No & 183 & 47.2 & Perceived health status & $3.20(0.86)$ & 35.2 \\
\hline \multicolumn{5}{|c|}{ Department of visit N (\%): Surgery 337 (83.4); Internal Medicine 67 (I6.6) } & \\
\hline
\end{tabular}

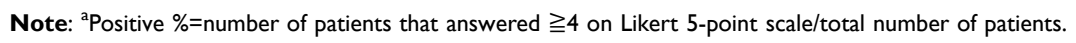


answered 4 or above (positive). Among the three domains of HL (Healthcare, HC-HL; Disease prevention, DP-HL; Health promotion, HP-HL), the lower mean value was HCHL, 3.63, and $38.9 \%$ of respondents answered positively. Among the four types of competencies of HL (Find information on health, FIH-HL; Understand information on health, UIH-HL; Judge information on health, JIH-HL; Apply information on health, AIH-HL), the lower mean value was FIHHL, 3.61 and JIH-HL, 3.60. 43.3\% and 41.1\%, respectively, answered positively. The HC scale had the highest mean value, 3.85 , and $63.7 \%$ of respondents answered positively. The mean value of UTA was the lowest, 3.08, and $34.2 \%$ of respondents answered positively (Table 1).

\section{Correlations Between the $\mathrm{HL}$ and Patient Demographics}

After $t$-test and ANOVA, results showed there were significant differences in age, education attainment, and history of chronic diseases for the HL. Those younger than 44 years had higher HL than those over 65. Those with high school education and college or above had higher HL than those with middle school or less. Patients without a history of chronic diseases had higher HL than those with a history of chronic diseases (Table 2). There were no significant differences in gender and department for the level of HL.

Regarding the relationships between the three domains of HL (HC-HL, DP-HL, HP-HL) and the four types of competencies (FIH-HL, UIH-HL, JIH-HL, AIH-HL) and demographics, we found no significant differences in age and history of chronic diseases on AIH-HL. There was no difference in the history of chronic diseases on DP-HL. However, on every aspect of domains and competencies of HL, those under 44 years old had higher than those over 65 years old; participants with high school education or college or above had higher than those with a middle school education or less, and patients without a history of chronic diseases had higher than those with history of chronic diseases (Table 2).

Using multiple regression, for all domains and competencies of HL, having a high school education was associated with greater HL relative to completing middle school or less. Perceived health status and watching health-related TV were all positively correlated with HL. In terms of age, those younger than 44 had greater on HL, DP-HL, UIH-HL, and JIH-HL than those over 65 years old, and there were no other significant correlates (Table 3).

\section{Relationships Among PPI, $\mathrm{HC}, \mathrm{HL}$ and GSE on SCM/UTA}

Table 4 shows PPI, HC, and HL all positively affect SCM ( $\beta$ value, respectively, $=0.260,0.240,0.192$ ). When replaced HL with HC-HL, DP-HL, HP-HL and FIH-HL, UIH-HL, JIH-HL, AIH-HL, the results show that HP-HL $(\beta=0.257)$, perceived health status $(\beta=0.095)$, and UIH-HL $(\beta=0.166)$ had positive correlations with SCM (Table 4). However, those over 65 years of age had greater UTA than those below the age of $44(\beta=-0.126,-0.145)$. HL $(\beta=0.327)$, HC-HL $(\beta=0.372)$, and JIU-HL $(\beta=0.329)$ were positively related to UTA (Table 4).

\section{Path Model for HL, GSE, PPI, and HC to SCM}

According to the path model analysis, HL has a direct positive effect on SCM (path coefficient = 0.176), and, through $\mathrm{HC}$, GSE, and PPI, has an indirect positive effect on SCM.

Table 2 ANOVA for Patient Characteristics and Health Literacy

\begin{tabular}{|c|c|c|c|c|c|}
\hline & \multicolumn{2}{|c|}{ Age } & \multicolumn{2}{|c|}{ Education Attainment } & \multirow{2}{*}{$\begin{array}{c}\text { History of Chronic } \\
\text { Disease }\end{array}$} \\
\hline & F-value & Post-Hoc & F-value & Post-Hoc & \\
\hline $\mathrm{HL}$ & $4.14^{*}$ & $1>3$ & $12.01 * * *$ & $|<2|<3$, & $2.40^{*}$ \\
\hline $\mathrm{HC}-\mathrm{HL}$ & $3.73^{*}$ & $1>3$ & $14.23 * * *$ & $|<2|<3$, & $2.56 *$ \\
\hline DP-HL & $3.13^{*}$ & $1>3$ & $7.12^{* * *}$ & $|<2|<3$, & 1.90 \\
\hline $\mathrm{HP}-\mathrm{HL}$ & $4.28^{*}$ & $1>3$ & $11.06 * * *$ & $|<2|<3$, & $2.20 *$ \\
\hline $\mathrm{FIH}-\mathrm{HL}$ & $3.86^{*}$ & $1>3$ & $12.49 * * *$ & $|<2|<3$, & $2.80 * *$ \\
\hline UIH-HL & $4.38^{*}$ & $1>3$ & $10.06 * * *$ & $|<2|<3$, & $2.31 *$ \\
\hline $\mathrm{JIH}-\mathrm{HL}$ & $4.60^{*}$ & $1>3$ & $11.74 * * *$ & $|<2|<3$, & $2.31 *$ \\
\hline AlH-HL & 1.92 & - & $7.43 * * *$ & $|<2|<3$, & 1.52 \\
\hline
\end{tabular}

Notes: $* \mathrm{P}<0.05, * * \mathrm{P}<0.0 \mathrm{I},{ }^{*} * \mathrm{P}<0.00 \mathrm{I}$. Age: $\leqq 44=\mathrm{I}, 45-64=2,65^{+}=3$. Education attainment: $\leqq$ Middle school $=\mathrm{I}$, High school $=2$, College or above $=3$. Sex and department of visit are all non-significant correlates. 
Table 3 Multiple Regression Analysis for Patient Characteristics and Health Literacy

\begin{tabular}{|c|c|c|c|c|c|c|c|c|}
\hline \multirow[t]{2}{*}{ Independent Variables } & HL & HC-HL & DP-HL & HP-HL & FIH-HL & UIH-HL & JH-HL & AIH-HL \\
\hline & $\beta$ value & $\beta$ value & $\beta$ value & $\beta$ value & $\beta$ value & $\beta$ value & $\beta$ value & $\beta$ value \\
\hline Age $\leqq 4465^{+}$as reference & $0.122 *$ & - & $0.131 *$ & - & - & $0.140 *$ & $0.150 *$ & - \\
\hline Edu $\leqq$ Middle school High school as reference & $-0.14 I^{*}$ & $-0.198 * * *$ & - & $-0.110 *$ & - & $-0.136^{*}$ & $-0.169 * *$ & $-0.116^{*}$ \\
\hline Perceived health status & $0.340 * * *$ & $0.285^{* * * *}$ & $0.327^{* *}$ & $0.328 * * *$ & $0.337^{* * *}$ & $0.27 \mid * * *$ & $0.330^{* * * *}$ & $0.316 * * *$ \\
\hline Watched health-related TV & $0.172 * *$ & $0.101 *$ & $0.159 * *$ & $0.210^{* * * *}$ & $0.158^{* *}$ & $0.196 * * *$ & $0.136 * *$ & $0.144^{* *}$ \\
\hline
\end{tabular}

Notes: $* \mathrm{P}<0.05,{ }^{*} \mathrm{P}<<0.01, * * * \mathrm{P}<0.00 \mathrm{I}$. Only variables of significant correlates are shown.

Table 4 Multiple Regression Analysis for Patient Characteristics, PPI, HC, HL, and SCM/UTA

\begin{tabular}{|c|c|c|c|c|c|c|}
\hline \multirow[t]{3}{*}{ Independent Variables } & \multicolumn{3}{|c|}{ Self-Care and Management (SCM) } & \multicolumn{3}{|c|}{ Understanding Treatment on Admission (UTA) } \\
\hline & Model I & Model 2 & Model 3 & Model I & Model 2 & Model 3 \\
\hline & $\beta$ value & $\beta$ value & $\beta$ value & $\beta$ value & $\beta$ value & $\beta$ value \\
\hline $\begin{array}{l}\text { Age } \leqq 4465^{+} \text {as reference } \\
\text { PPI } \\
\text { HC } \\
\text { Perceived health status }\end{array}$ & $\begin{array}{c}0.260 * * * \\
0.240 * * * \\
-\end{array}$ & $\begin{array}{c}0.27 \text { I } * * * \\
0.268 * * * \\
-\end{array}$ & $\begin{array}{c}0.265^{* * *} \\
0.229 * * * \\
0.095^{*}\end{array}$ & $-0.126^{*}$ & - & $-0.145^{*}$ \\
\hline $\begin{array}{l}\text { HL } \\
\text { HP-HL } \\
\text { UIH-HL } \\
\text { HC-HL } \\
\text { JIH-HL }\end{array}$ & $0.192 * *$ & $0.257 * * *$ & $0.166 *$ & $0.327 * * *$ & $0.372 * * *$ & $0.329 * *$ \\
\hline
\end{tabular}

Notes: $* \mathrm{P}<0.05, * * \mathrm{P}<0.01, * * * \mathrm{P}<0.001$. Only variables of significant correlates are shown.

GSE has a direct positive effect on SCM (path coefficient = 0.169 ) and can also indirectly positively affect SCM through PPI and HC. PPI has a direct positive effect on SCM (path coefficient $=0.241)$ and can also indirectly positively affect SCM through HC. HC has a direct positive effect on SCM (path coefficient $=0.252$ ) as shown in Figure 1 .

\section{Discussion}

Hospitals have the potential to take a role as independent community health centers, with a responsibility to promote preventive health. Along with diagnosis and treatment, patients could also improve their health literacy via information and communication. This study provides insight into contexts in which health literacy plays an important role. It therefore suggests arenas in which health education interventions could be developed.

These findings differ to those of a population-based study that showed health literacy was 34.4 on a scale of 50 (from $0=$ the lowest health literacy to $50=$ the highest health literacy) in Taiwan. ${ }^{33}$ In a European study, $52.5 \%$ of the total sample had adequate health literacy ${ }^{22}$ using the HLS-EU. The reason could be that the selection of participants was different. In our study, patients at preadmission testing center were selected. They were ill and had limited health literacy with some difficulty in accessing, understanding, evaluating, and applying health information to manage their own health, ${ }^{24}$ while a more general population sample would be healthy or at risk of illness. Therefore, may be the proportion of adequate health literacy is lower than that for the general public or outpatients. Healthcare health literacy is not as in Taiwan study indicated somewhat higher than health promotion health literacy, but is the lowest of the three domains of health literacy (Healthcare, Disease prevention, and Health promotion). As patients prepare for treatment of their condition, healthcare health literacy is at its most needed, and this study shows that the mean value of understanding treatment on admission is only 3.08 , which accounts for $34.2 \%$ answering positive. Lower ability to find health information and judge health information may result in the patients who do not understand the treatment for which they are being admitted.

The US Department of Health and Human Services (HHS) - a disease prevention and health organization - 


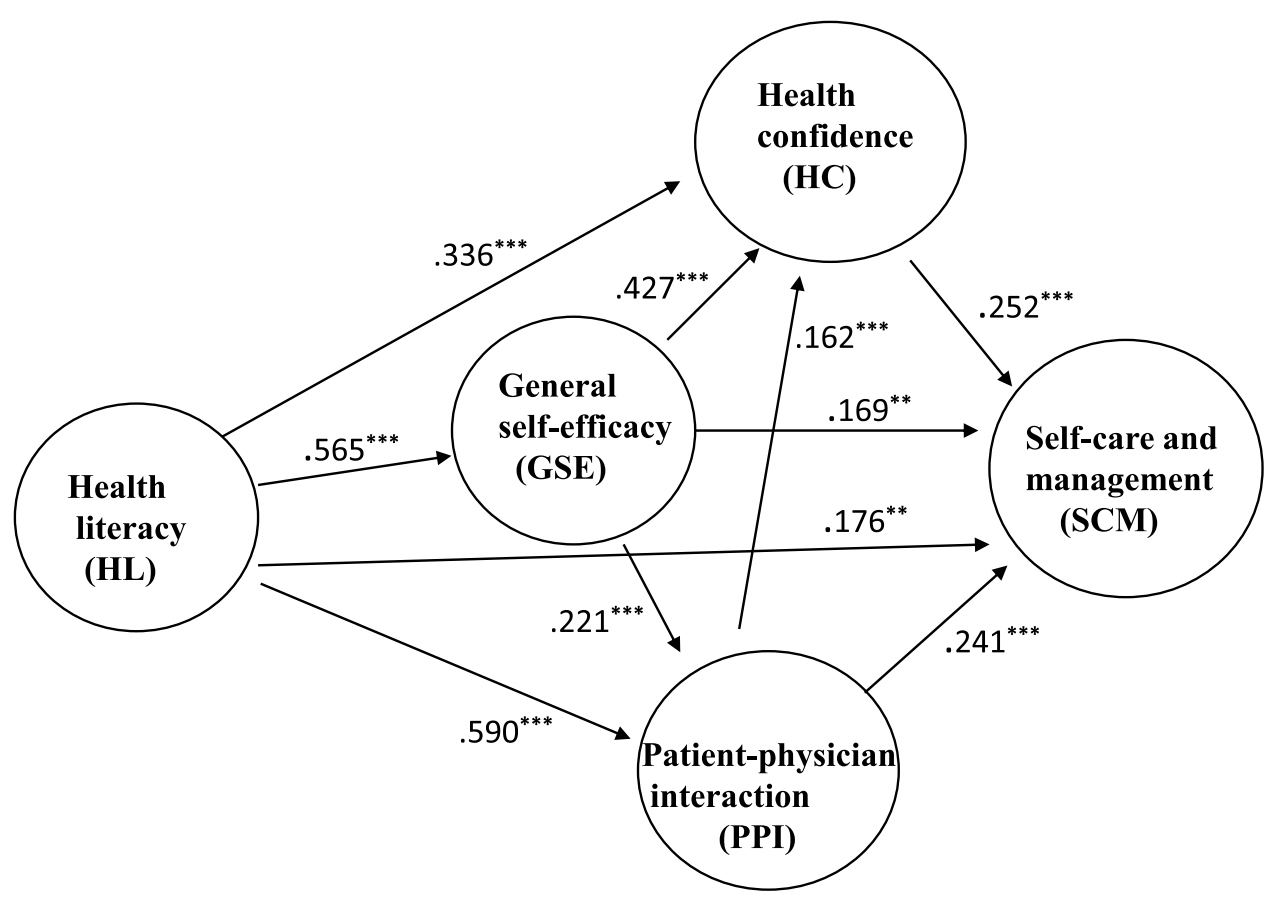

Figure I Pathways for health literacy, general self-efficacy, patient-physician interaction, health confidence, and self-care and management. $* * \mathrm{P}<0.0 \mathrm{I}, * * * \mathrm{P}<0.00 \mathrm{I}$.

suggests that organizations have a responsibility to address health literacy. ${ }^{34}$ Developing hospital-based health education programs for patients being admitted is a big challenge. It encompasses improving the health literacy of patients during hospitalization, and improving understanding and management of self-care after discharge.

With regard to correlations between the health literacy and patient demographics, higher health literacy is significantly associated with a younger age, higher education attainment, perceived health status, and a higher frequency of watching health-related TV, which is consistent with the literature reviewed. ${ }^{22,23,33,35}$ In addition, health literacy was not found to differ by gender or hospital department. This reflects that when patients visit different departments based on their health needs or demands, the health-care provider should take into account their different domains and competencies of health literacy and tailor appropriate strategies to meet patients' individual needs. At the same time, however, developing health literacy is a process of accumulation, in which people need to build knowledge and skills through their lifetime to manage their own health and care. ${ }^{24}$

With regard to the relationships of patient-physician interaction, health confidence, health literacy and general self-efficacy on self-care and management/understanding treatment on admission, people tend to depend more on the health-care system than on themselves to manage health. ${ }^{36}$
Health literacy is recognized as an essential determinant of health and enables better self-care with fewer health risks. ${ }^{37}$ It can be thought of as the compass needed to navigate the system. ${ }^{11}$ The results in this study show that health literacy, health promotion health literacy and ability to understanding health information positively affected self-care and management. This can be explained based on Nutbeam health literacy ${ }^{38}$ where health literacy is regarded as a personal "asset". It can be further developed to encompass adult learning, competence in understanding health information, judgment and decision-making in terms of health promotion health literacy. In addition, when health literacy is seen as a clinical "risk", it could lead to a range of changes in clinical practice and organization. Better patient-physician interaction and sharing of knowledge between clinicians and patients and their families can contribute to successful self-management.

Health literacy, healthcare health literacy, and ability to judge health information were positively related to understanding treatment on admission, and this study showed that only $34.2 \%$ of respondents really understood treatment on admission. This demonstrates that in-patients are at the most concerned and anxious about their health problem and need interventions to improve patients' ability to interpret, filter, judge and evaluate pertinent health information so that adequate general health literacy was warranted. 
With the COVID-19 pandemic, health literacy has become more important than ever. Everyone needs to be informed and educated about the current situation and any preventive treatment against the coronavirus. ${ }^{34}$ Healthcare providers, therefore, should actively develop easy-tounderstand, well-judged information and instructions for patients as a cross-cutting priority to improve the quality of care. ${ }^{39}$

Regarding the path model for health literacy, general self-efficacy, patient-physician interaction, and health confidence to self-care and management, this is expected to further help a hospital allocate resources appropriately and effectively for both medical treatment and for developing health literacy. According to the path analysis, health literacy is a critical facilitating factor in improving selfcare and management because health confidence, general self-efficacy, and patient-physician interaction indirectly positively affect self-care and management. General selfefficacy, patient-physician interaction, and health confidence have a direct positive effect on self-care and management, general self-efficacy and patient-physician interaction. Health confidence also has an indirect positive effect on self-care and management and general selfefficacy and patient-physician interaction has an indirect positive effect on self-care and management.

Recent literature has shown the importance of moving beyond an individual focus to consider health literacy as an interaction between the demands of health systems and the skills of individuals. ${ }^{24}$ Health literacy is a multidimensional concept and consists of different key components alongside recognition of individual and health system factors that influence a person's level of health literacy, as well as the pathways that relate health literacy to health outcomes. ${ }^{24}$ Paasche-Orlow and Wolf ${ }^{40}$ also indicated that HL should be viewed as both a patient and a system phenomenon. They proposed a conceptual causal model that recognizes both individual and system-level factors that affect access to healthcare, patient-provider relationships, and self-care activities. This is consistent with the path model for health literacy, general selfefficacy, patient-physician interaction and health confidence to self-care and management found in this study. This may be explained why a patient's low health literacy causes adverse outcomes through lower general selfefficacy and health confidence, lack of knowledge and skills, attitudinal and motivational differences, ineffective patient-physician interaction, and self-care behaviors. ${ }^{40-42}$ Therefore, increasing patients' ability to understand and engage in their healthcare is an international priority and a main driver for improving health-related outcomes for patients is to increase health literacy. It is time to shift the focus from patient to provider, and look at what the healthcare provider can do to make changes that make it easy for patients to understand health information. ${ }^{3}$

The limitations of this study include the fact that participant inclusion was based on patient consent, so there may have been selection bias. The study sample also came from a single regional hospital, so may not be generalizable. We also acknowledge that health literacy measured on an individual's current abilities and the complexity of their health-care needs may vary depending on the specific health condition. Further study is needed to evaluate the health literacy of discharged patients to more fully understand hospital performance.

\section{Conclusions}

This study provides insights into the necessity and challenges for health education programs in hospitals. $36.1 \%$ of patients in our study had adequate health literacy. There were significant differences in age, education attainment, and history of chronic diseases for health literacy. 65.8\% of patients did not understand the treatment for which they were being admitted. There needs, therefore, to be an improvement in patients' health literacy. Strengthening health promotion health literacy and ability to understand health information would help improve the ability of selfcare and management. Strengthening healthcare health literacy and ability to judge health information would help patients understand their treatment. Health education programs cannot be one-size-fits-all. To help patients change their behavior, health-care decision-makers must make the change easy. Hospitals should take on this role to develop patients' understanding and should make appropriate modifications, such as developing non-print materials and designing user-friendly, diverse health literacy materials. This would facilitate more meaningful relationships between patients and caregivers.

\section{Abbreviations}

HL, health literacy; HC, health confidence; GSE, general self-efficacy; PPI, patient-physician interaction; DP, disease prevention; HP, health promotion; HC-HL, healthcare health literacy; PEPPI, perceived efficacy in patient-physician interactions; SCM, self-care and management; UTA, understanding treatment on admission; FIH, find information on 
health; UIH, understand information on health; JIH, judge information on health; AIH, apply information on health.

\section{Data Sharing Statement}

The data was collected from the patient's self-administered questionnaire with patient consent during the current study. The datasets are not publicly available, but are accessible from the corresponding author on reasonable request.

\section{Ethics Approval and Informed Consent}

This study was approved by the review board of National Taiwan University Hospital Hsin-Chu Branch (108免2). All participants were fully informed about the content of the study, and understood they had a right to withdraw from the study at any time. Written informed consent was obtained before the interviews. This study was conducted in accordance with the Declaration of Helsinki.

\section{Acknowledgments}

The authors would like to thank the participants who agreed to self-administered questionnaire.

\section{Funding}

This study was supported by grants from the National Taiwan University Hospital, Hsin-Chu Branch, (108HCH040). The funders had no role in the study design, data collection, data analysis or interpretation of the results, or in the writing of the manuscript.

\section{Disclosure}

The authors declare they have no competing interests.

\section{References}

1. Uddin I. Development of health promotion in the hospital settingprogramme development. Int $J$ Health Promot Educ. 2001;39 (2):40-43. doi:10.1080/14635240.2001.10806148

2. Groene O, Jorgensen SJ. Health promotion in hospitals - a strategy to improve quality in health care. Eur J Public Health. 2005;15(1):6-8. doi:10.1093/eurpub/cki100

3. Raynor T. Health literacy: is it time to shift our focus from patient to provider? BMJ. 2012;344:e2188. doi:10.1136/bmj.e2188

4. Baker D, Parker R, Williams MV, Nurss J. The relationship of patient reading ability to self-reported health and use of health services. $\mathrm{Am}$ J Public Health. 1997;87(6):1027-1039. doi:10.2105/AJPH.87.6.1027

5. Kyle S, Shaw D. Doctor-patient communication, patient knowledge and health literacy: how difficult can it all be? Bull Roy Coll Surg Engl. 2014;96(6):e9-e13. doi:10.1308/rcsbull.2014.96.6.e9

6. Sim D, Yuan SE, Yun JH. Health literacy and physician-patient communication: a review of the literature. Int $J$ Commun Health. 2016;10:101-114.
7. Health literacy. Available from: https://www.hpa.gov.tw/EngPages/ Detail.aspx?nodeid=1074\&pid=10535. Accessed July 23, 2021.

8. Dewalt DA, Berkman ND, Sheridan S, Lohr KN, Pignone MP. Literacy and health outcomes: a systematic review of the literature. J Gen Intern Med. 2004;19(12):1228-1239. doi:10.1111/j.15251497.2004.40153.x

9. Berkman ND, Sheridan SL, Donahue KE, Halpern DJ, Crotty K. Low health literacy and health outcomes: an updated systematic review. Ann Intern Med. 2011;155(2):97-107. doi:10.7326/0003-4819-1552-201107190-00005

10. Eichler K, Wieser S, Brügger U. The costs of limited health literacy: a systematic review. Int $J$ Public Health. 2009;54(5):313-324. doi:10.1007/s00038-009-0058-2

11. What is health literacy and why do I need it? Available from: https:// health.usnews.com/health-care/articles/2018-12-14/what-is-healthliteracy-and-why-do-i-need-it. Accessed July 23, 2021.

12. Hibbard JH, Greene J. What the evidence shows about patient activation: better health outcomes and care experiences; fewer data on costs. Health Aff. 2013;32:207-214. doi:10.1377/hlthaff.2012.1061

13. Benson T, Potts HW, Bark P, Bowman C. Development and initial testing of a Health Confidence Score (HCS). BMJ Open Qual. 2019;8:e000411. doi:10.1136/bmjoq-2018-000411

14. Wasson J, Coleman EA. Health confidence: a simple, essential measure for patient engagement and better practice. Fam Pract Manag. 2014;21(5):8-12.

15. Wasson JH, Baker NJ. Balanced measures for patient-centered care. $J$ Ambul Care Manage. 2009;32:44-55. doi:10.1097/01. JAC.0000343123.53585.51

16. Lepore M, Wild D, Gil H, et al. Two useful tools: to improve patient engagement and transition from the hospital. J Ambul Care Manage. 2013;36:338-344. doi:10.1097/JAC.0b013e3182a3317a

17. Barlow J, Wright C, Sheasby J, Turner A, Hainsworth J. Self-management approaches for people with chronic illness: a review. Patient Educ Couns. 2002;48(2):177-187. doi:10.1016/S0738-3991(02)00032-0

18. Stars I. Health literacy as a challenge for health education. In SHS Web of Conferences; 2018;40:02004.

19. Kerka S. Health and adult literacy. Practice application Brief No. 7. ERIC Clearinghouse on adult, career, and vocational education, center on education and training for employment, College of Education, The Ohio State University; 2000.

20. Palumbo R. Designing health-literate health care organization: a literature review. Health Serv Manage Res. 2016;29(3):79-87. doi:10.1177/0951484816639741

21. HLS-EU Consortium. Comparative report of health literacy in eight EU member states. The European Health Literacy Project 20092012. Maastricht University; 2012.

22. Sørensen K, Pelikan JM, Röthlin F, et al. Health literacy in Europe: comparative results of the European health literacy survey (HLS-EU). Eur J Public Health. 2015;25(6):1053-1058. doi:10.1093/eurpub/ckv043

23. Van Duong T, Chang PW, Yang SH, et al. A new comprehensive short-form health literacy survey tool for patients in general. Asian Nurs Res. 2017;11(1):30-35.

24. Sorensen K, Van den Broucke S, Fullam J, et al. Health literacy and public health: a systematic review and integration of definitions and models. BMC Public Health. 2012;12(1):80. doi:10.1186/1471-2458-12-80

25. Bandura A. Self-Efficacy: The Exercise of Control. New York: Freeman; 1997.

26. Luszczynska A, Gutiérrez-Doña B, Schwarzer R. General self-efficacy in various domains of human functioning: evidence from five countries. Int $J$ Psychol. 2005;40(2):80-89. doi:10.1080/ 00207590444000041

27. Schwarzer R, Jerusalem M. Generalized self-efficacy scale. In: Weinman J, Wright S, Johnston M, editors. Measures in Health Psychology: A User's Portfolio. Causal and Control Beliefs. Windsor, UK: NFER-Nelson; 1995. 
28. Maly RC, Frank JC, Marshall GN, DiMatteo MR, Reuben DB. Perceived efficacy in patient-physician interactions (PEPPI): validation of an instrument in older persons. J Am Geriatr Soc. 1998;46 (7):889-894. doi:10.1111/j.1532-5415.1998.tb02725.x

29. Ten Klooster PM, Oostveen JCM, Zandbelt LC, et al. Further validation of the 5-item Perceived Efficacy in Patient-Physician Interactions (PEPPI-5) scale in patients with osteoarthritis. Patient Educ Couns. 2012;87(1):125-130. doi:10.1016/j.pec.2011.07.017

30. Health status patient measures. Available from: https://r-outcomes.com/ r-measures/patient/other/health-confidence/. Accessed July 25, 2021.

31. Benson T, Potts HW, Bowman C. Development and validation of a short health confidence score. Value Health. 2016;19(3):A94. doi:10.1016/j.jval.2016.03.1742

32. Self-Management Resource Center. Manage disease in general scale. Available from: https://www.selfmanagementresource.com/docs/pdfs/ English_-_chronic_disease_self-efficacy_scales_32.pdf. Accessed March 13, 2019.

33. Duong VT, Lin IF, Sorensen K, et al. Health literacy in Taiwan: a population-based study. Asia Pac J Public Health. 2015;27 (8):871-880. doi:10.1177/1010539515607962

34. How to improve your health literacy as a patient? Available from: https://www.losgatosdoc.com/2020/10/30/how-to-improve-yourhealth-literacy-as-A-patient-2/. Accessed July 11, 2021.
35. Toci E, Burazeri G, Myftiu S, Sørensen K, Brand H. Health literacy in a population-based sample of adult men and women in a South Eastern European country. J Public Health. 2016;38(1):6-13. doi:10.1093/pubmed/fdv006

36. Ratzan SC. Health literacy: communication for the public good. Health Promot Int. 2001;16(2):207-214. doi:10.1093/heapro/16.2.207

37. Ishikawa H, Yano E. Patient health literacy and participation in the healthcare process. Health Expect. 2008;11:113-122. doi:10.1111/ j.1369-7625.2008.00497.x

38. Nutbeam D. The evolving concept of health literacy. Soc Sci Med. 2008;67(12):2072-2078. doi:10.1016/j.socscimed.2008.09.050

39. Koster ES, Schmidt A, Philbert D, van de Garde EMW, Bouvy ML. Health literacy of patients admitted for elective surgery. J Public Health. 2017;25:181-186. doi:10.1007/s10389-016-0774-z

40. Paasche-Orlow MK, Wolf MS. The causal pathways linking health literacy to health outcomes. Am J Health Behav. 2007;31(Suppl 1): S19-S26. doi:10.5993/AJHB.31.s1.4

41. Von Wagner C, Steptoe A, Wolf M, Wardle J. Health literacy and health actions: a review and a framework from health psychology. Health Educ Behav. 2009;36:860-877. doi:10.1177/1090198108322819

42. Osborn CY, Paasche-Orlow MK, Bailey SC, Wolf MS. The mechanisms linking health literacy to behavior and health status. Am J Health Behav. 2011;35:118-128. doi:10.5993/AJHB.35.1.11
Risk Management and Healthcare Policy

\section{Publish your work in this journal}

Risk Management and Healthcare Policy is an international, peerreviewed, open access journal focusing on all aspects of public health, policy, and preventative measures to promote good health and improve morbidity and mortality in the population. The journal welcomes submitted papers covering original research, basic science, clinical \& epidemiological studies, reviews and evaluations,

\section{Dovepress}

guidelines, expert opinion and commentary, case reports and extended reports. The manuscript management system is completely online and includes a very quick and fair peer-review system, which is all easy to use. Visit http://www.dovepress.com/testimonials.php to read real quotes from published authors. 